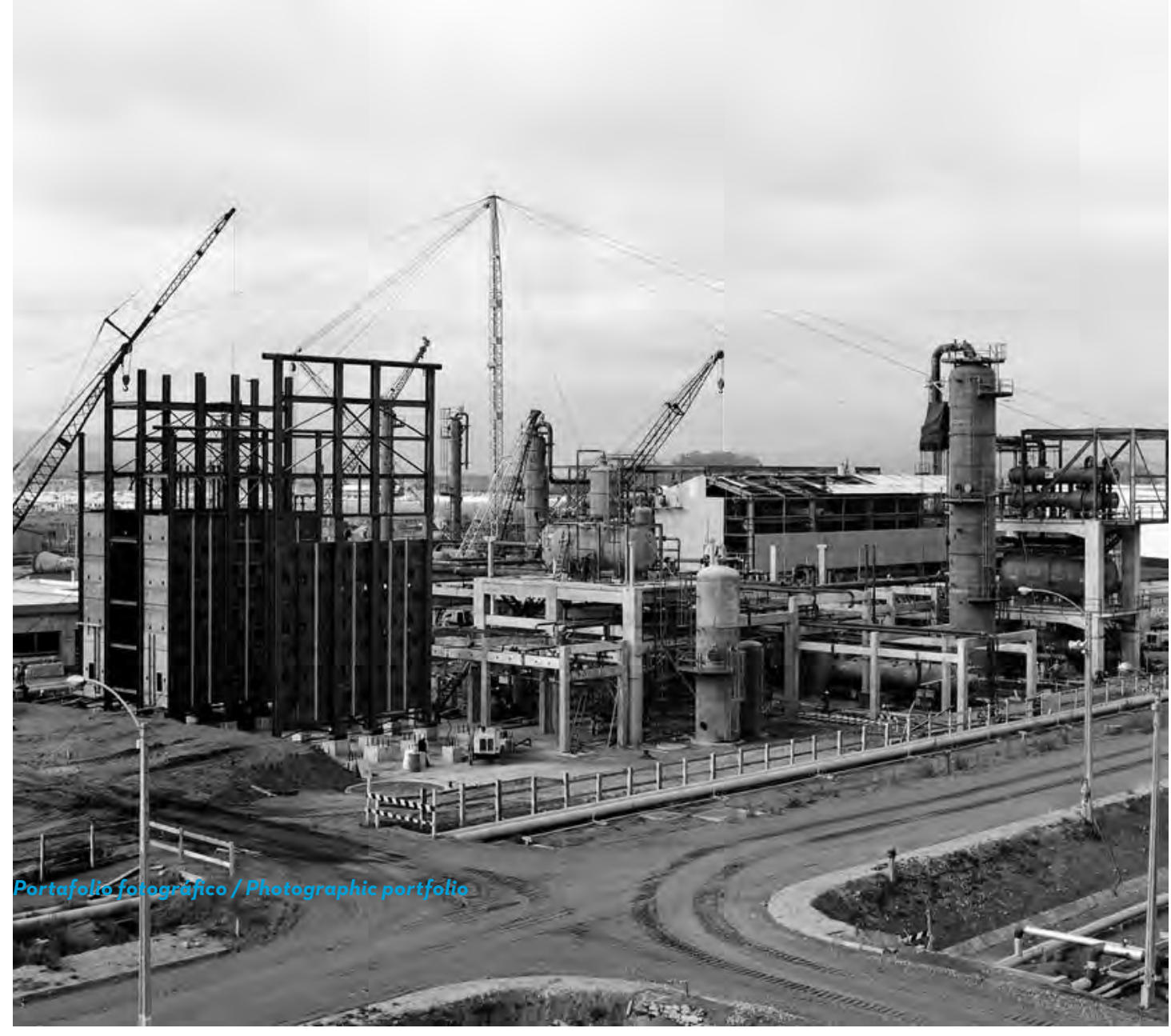

\title{
LA FOTOGRAFÍA DE JACK CEITELIS
}

\section{CARLA FRANCESCHINI}

Curadora de fotografía

Museo Histórico Nacional, Santiago, Chile

Como documentos históricos, las fotografías de Jack Ceitelis permiten observar el desarrollo de la infraestructura de Chile durante el siglo Xx. Pero sus encuadres, hechos con una mirada más artística que publicitaria o documental, van más allá del mero registro: logran hacernos ver la infraestructura con un tinte épico, sobre todo en un contexto previo a la economía de servicios, donde estas obras eran claves para asegurar el desarrollo productivo del país.

Palabras clave Infraestructura

Paisaje

Industria

Desarrollo

Chile 


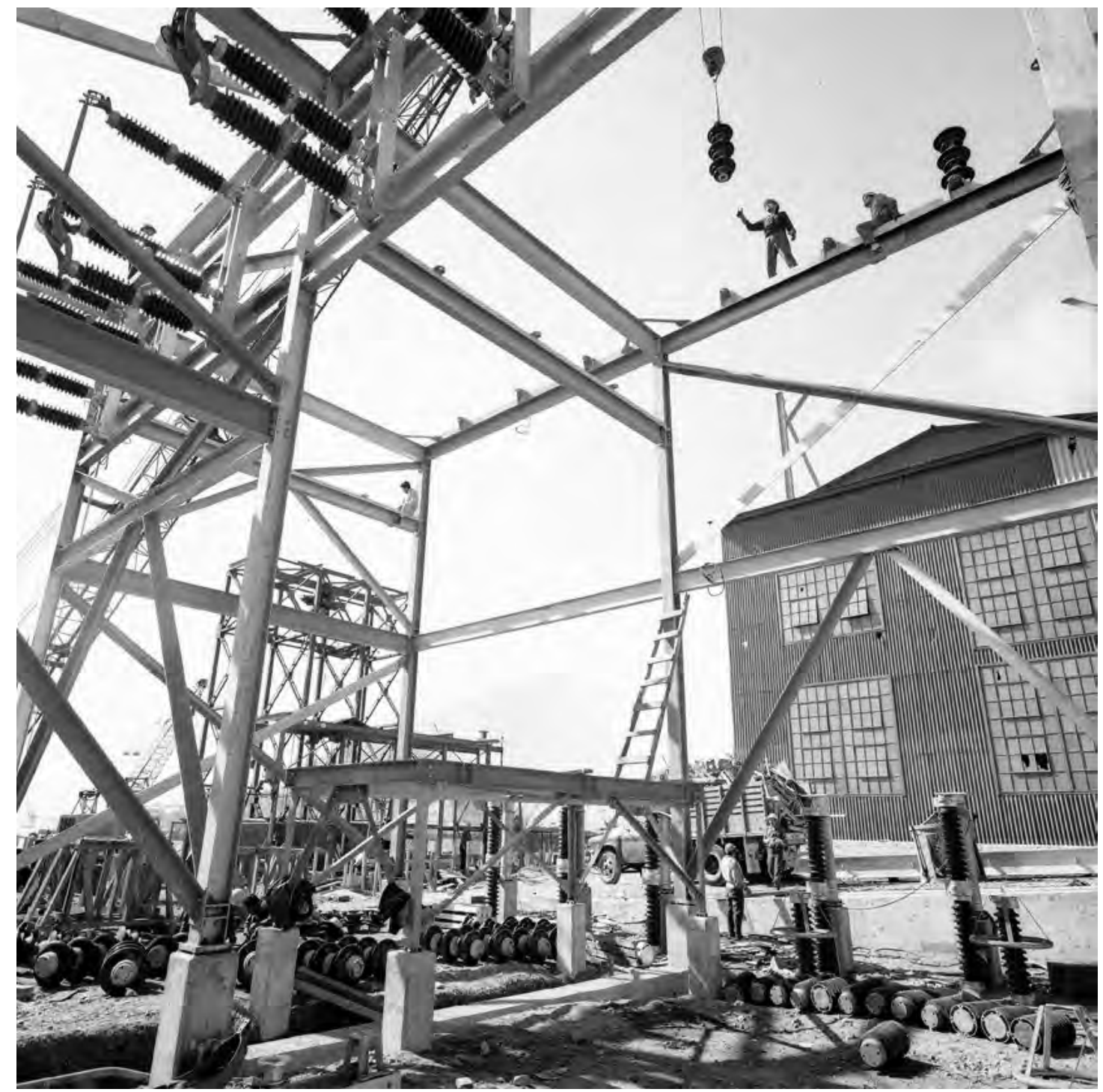

Montaje patio de alta tensión. Ovalle Moore s. A., 1981./ High voltage patio assembly. Ovalle Moore s.A., 1981. (c) Colección Museo Histórico Nacional a vasta trayectoria del fotógrafo de origen

lituano Jack Ceitelis (I930), avecindado en

Chile a partir de los años 40, se ve reflejada en la adquisición de la colección de paisajes y fotografía industrial realizada en 2016 por el Museo Histórico Nacional (MHN).

Además de extenso (tras haber ejercido durante más de 50 años), el trabajo de Ceitelis es muy variado y viene a complementar el acervo custodiado por el primer archivo fotográfico nacional, cuyo acopio comenzó a fines de los años 70 en el MHN.

Pese a tener una formación autodidacta, Ceitelis se reconoce seguidor de Antonio Quintana (I904I972), quien fue un referente para la generación de fotógrafos de mediados del siglo xx en Chile.

Junto a los paisajes que caracterizan la obra de Ceitelis, encontramos que una parte importante de su trabajo está dedicado al registro de la infraestructura industrial de nuestro país durante el siglo xx. 


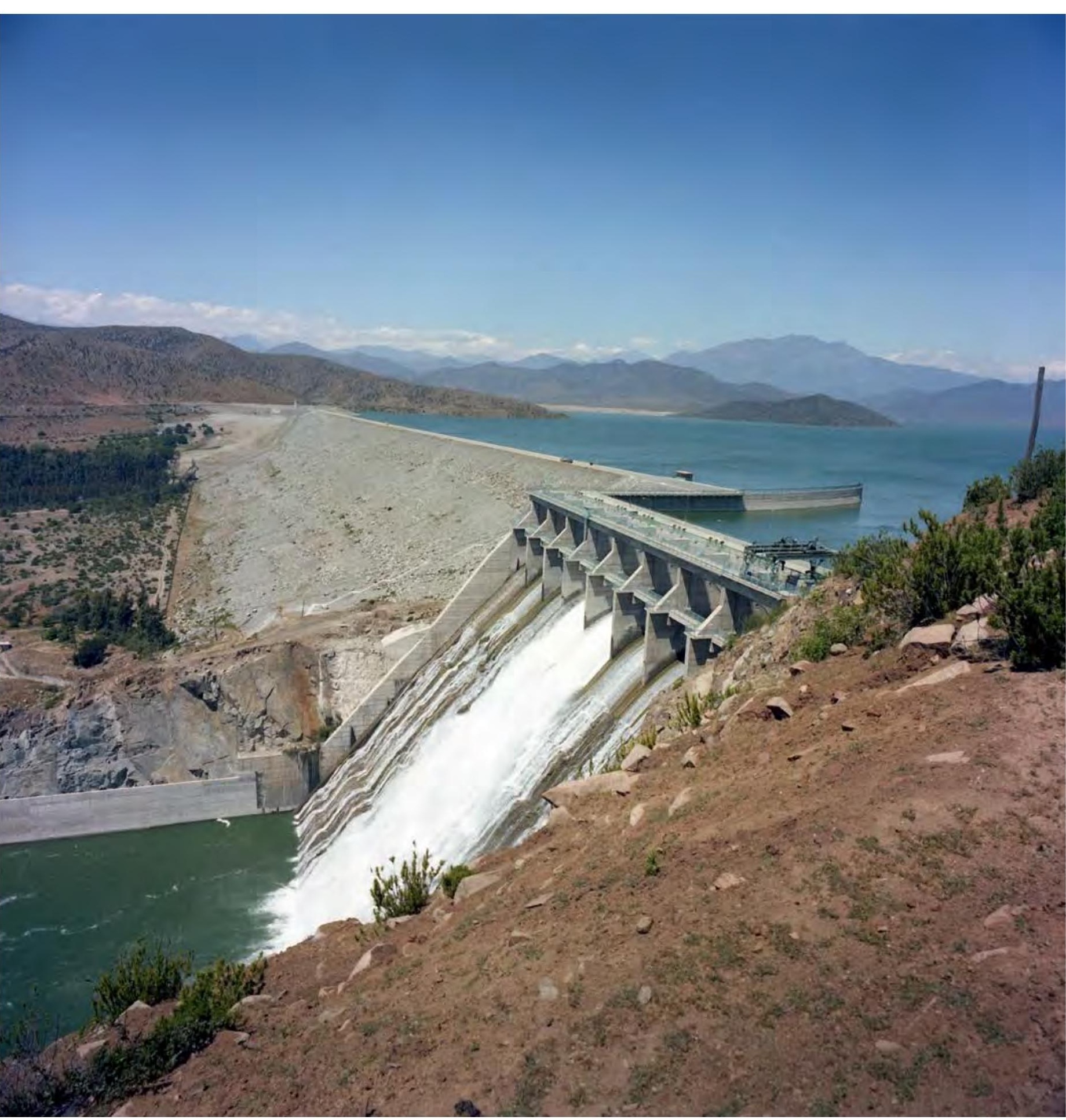

Embalse La Paloma.

Constructora Gardilcic

Ltda., 1983. / La Paloma

reservoir. Gardilcic

Construction Company

Ltd., 1983. (C) Colección

Museo Histórico Nacional 


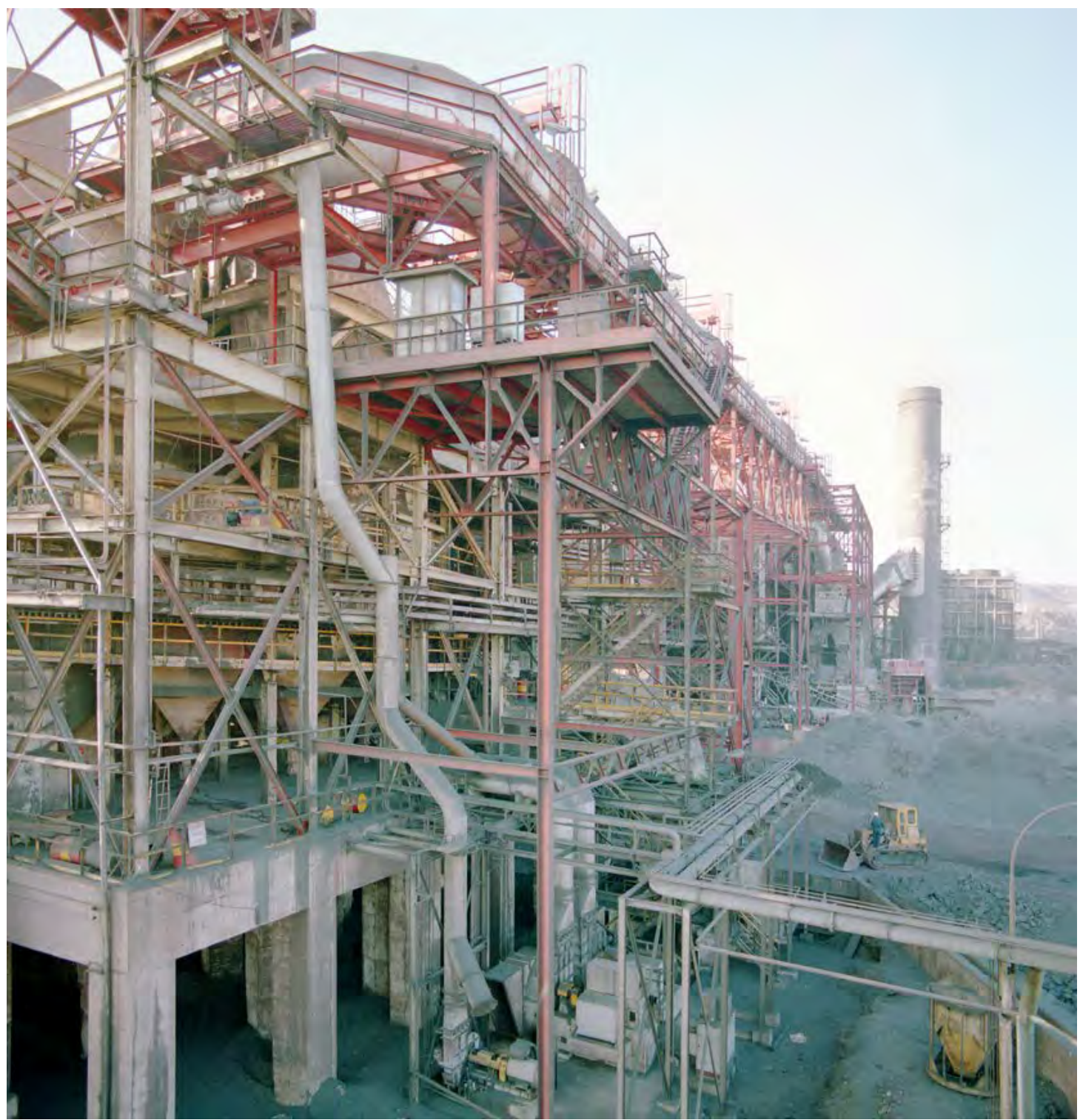

Ampliación planta de pellets. CAP S.A., 1989. Pellet plant expansion. CAP S. A., 1989. (C) Colección Museo Histórico Nacional

Características son sus imágenes de grandes estructuras de metal en las que resulta complejo mantener las proporciones espaciales y humanas. Represas, industrias y desarrollo de procesos son algunas de las principales temáticas capturadas por el fotógrafo.

Ceitelis aplica correctos y creativos encuadres que, en muchas ocasiones, están más cercanos a obras de arte moderno que al registro fotográfico como tal, ampliando así la mirada de la fotografía industrial. Es en este contexto que, en la década del 5o, el fotógrafo expone en el Museo Nacional de Bellas Artes junto al Grupo Rectángulo.

Para el Museo Histórico Nacional es fundamental conservar y difundir el trabajo de importantes fotógrafos como Jack Ceitelis, cuya producción no sólo es un referente para el patrimonio nacional, sino también una fuente de documentación e inspiración para las nuevas generaciones. ARQ 


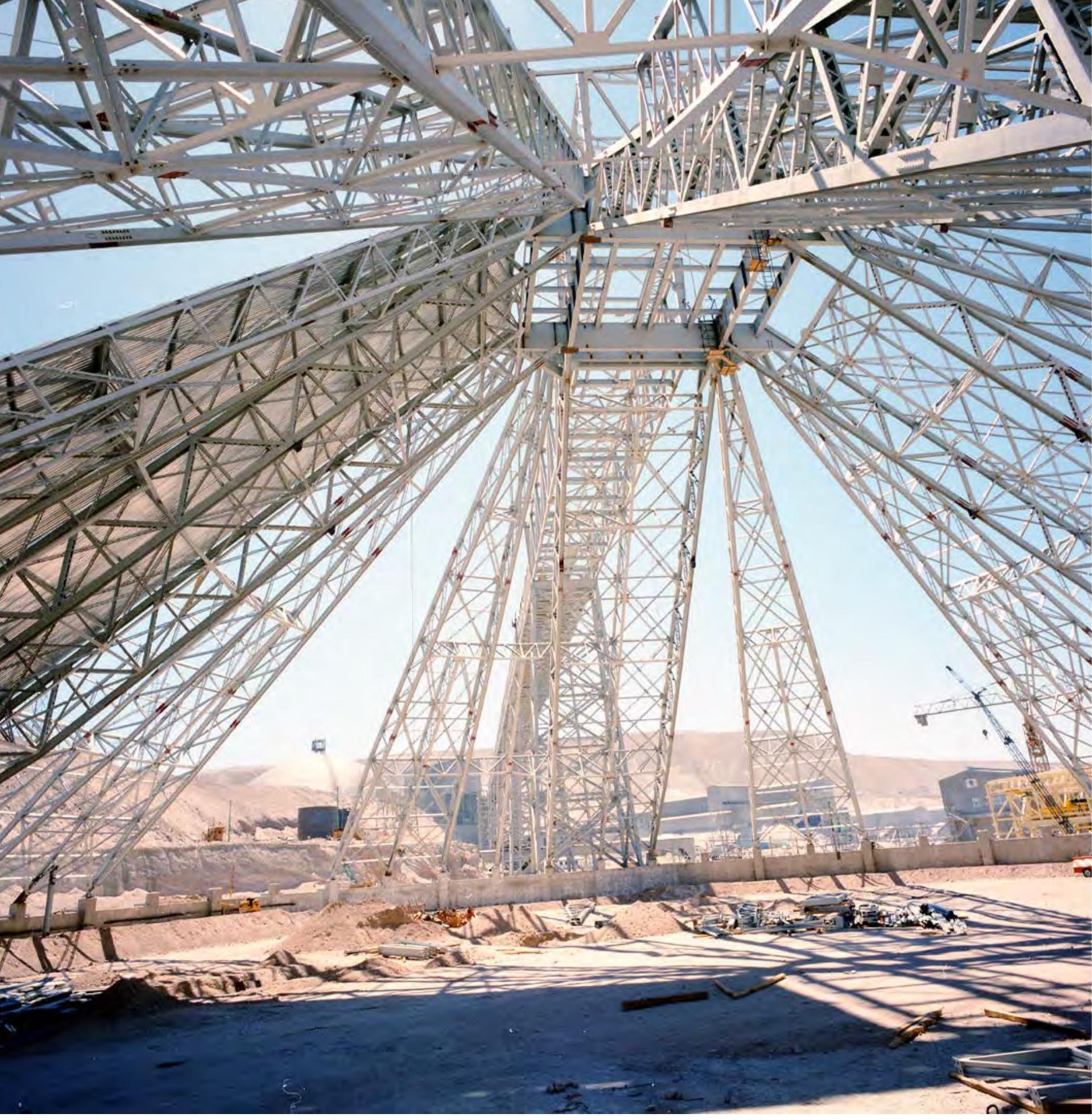

\section{Carla Franceschini}

<carla.franceschini@mhn.cl>

Licenciada en artes plásticas con mención en fotografía, Universidad de Chile, I989. Magíster en Artes, mención en teoría e historia del arte, Universidad de Chile, 2007. Como artista visual, ha realizado exposiciones colectivas entre 1998 y 2015 en distintas instituciones dentro y fuera del país. Es autora junto a llonka Csillac de Chile en Iooo fotografías (Pehuén Editores, 2015). Desde 2009 ha curado exposiciones de fotografía en la Biblioteca Nacional, el Museo de Bellas Artes y el Museo Histórico Nacional, donde actualmente se desempeña como curadora de fotografía.
Construcción de domo

para concentrado,

Chuquicamata.

CODELCO, 1988.

Formula dome

construction,

Chuquicamata.

CODELCO, 1988.

(C) Colección Museo

Histórico Nacional 